\title{
BMJ Open Associations between antenatal and perinatal risk factors and cerebral palsy: a Swedish cohort study
}

\author{
Anna Jöud (ib , ${ }^{1}$ Andréa Sehlstedt, ${ }^{1}$ Karin Källén, ${ }^{2}$ Lena Westbom, ${ }^{3}$ Lars Rylander ${ }^{1}$
}

To cite: Jöud A, Sehlstedt A, Källén $\mathrm{K}$, et al. Associations between antenatal and perinatal risk factors and cerebral palsy: a Swedish cohort study. BMJ Open 2020;10:e038453. doi:10.1136/ bmjopen-2020-038453

- Prepublication history for this paper is available online. To view these files, please visit the journal online (http://dx.doi org/10.1136/bmjopen-2020038453).

Received 12 March 2020 Revised 25 June 2020 Accepted 30 June 2020

D) Check for updates

(c) Author(s) (or their employer(s)) 2020. Re-use permitted under CC BY-NC. No commercial re-use. See rights and permissions. Published by BMJ.

${ }^{1}$ Institution for Laboratory medicine, Division of Environmental and occupational medicine, Lund University, Lund, Sweden

${ }^{2}$ Clinical sciences Lund, Centre of reproductive epidemiology, Lunds Universitet, Lund, Sweden ${ }^{3}$ Clinical Sciences Lund, Division of pediatrics, Lund University, Lund, Sweden

Correspondence to

Anna Jöud;

anna.joud@med.lu.se

\section{ABSTRACT}

Objectives To investigate known and suggested risk factors associated with cerebral palsy in a Swedish birth cohort, stratified by gestational age.

Setting Information on all births between 1995 and 2014 in Skåne, the southernmost region in Sweden, was extracted from the national birth register.

Participants The cohort comprised a total of 215217 children. Information on confirmed cerebral palsy and subtype was collected from the national quality register for cerebral palsy (Cerebral Palsy Follow-up Surveillance Programme).

Primary and secondary outcome measures We calculated the prevalence of risk factors suggested to be associated with cerebral palsy and used logistic regression models to investigate the associations between potential risk factors and cerebral palsy. All analyses were stratified by gestational age; term ( $\geq 37$ weeks), moderately or late preterm (32-36 weeks) and very preterm ( $<32$ weeks). Results In all, 381 (0.2\%) children were assigned a cerebral palsy diagnosis. Among term children, maternal preobesity/obesity, small for gestational age, malformations, induction, elective and emergency caesarian section, Apgar $<7$ at 5 min and admission to neonatal care were significantly associated with cerebral palsy (all $p$ values $<0.05$ ). Among children born moderately or late preterm, small for gestational age, malformations, elective and emergency caesarian section and admission to neonatal care were all associated with cerebral palsy (all $p$ values $<0.05$ ), whereas among children born very preterm no factors were significantly associated with the outcome (all $p$ values $>0.05$ ).

Conclusion Our results support and strengthen previous findings on factors associated with cerebral palsy. The complete lack of significant associations among children born very preterm probably depends on to the small number of children with cerebral palsy in this group.

\section{INTRODUCTION}

Cerebral palsy (CP) is one of the most common physical disabilities in children, with a prevalence of 2-2.5 per 1000 live births. ${ }^{12} \mathrm{CP}$ is an umbrella term that describes a clinical symptom complex consisting of movement and posture disorders that are permanent (but not necessarily unchanging) and due to a non-progressive lesion/interference/ abnormality in the developing/immature

\section{Strengths and limitations of this study}

- This is a population-based study where we had the possibility to include a number of factors simultaneously, both antenatal and perinatal factors.

- The use of routinely and prospectively collected data eliminated the risk for recall bias.

- The large sample size enabled us to stratify all analyses on gestational age.

- However, the group very preterm was small making conclusions difficult to draw.

brain. ${ }^{3}$ There is usually a large gap in time from the occurrence of the brain damage until a CP diagnosis can be verified, which complicates the study of possible aetiologies. ${ }^{4}$

The total prevalence of $\mathrm{CP}$ in the developed world has been relatively stable since the 1950 s, although the distribution of different CP subtypes and severity levels have changed during the decades. Increased survival of newborns in successively earlier gestational age, with initially high incidences of cerebral insults, contributed to an increasing CP prevalence during a period. Lately, a decreased CP prevalence has been seen in several gestational age groups. ${ }^{5-8}$ A better understanding of the aetiology and risk factors for CP would hopefully result in more preventive measures. A decrease in the number of cases would be of immense benefit on the individual as well as on the socioeconomic level. ${ }^{9}$

Birth asphyxia was long thought to be the main cause of CP. Although the definition of birth asphyxia has varied, it has often been based on different non-specific clinical signs, not taking into account that a newborn infant has a very limited range of responses. A study investigating 23 papers on intrapartum risks of $\mathrm{CP}$ found that the definitions of birth asphyxia as well as CP were heterogeneous and concluded that confusion of proximal effects with causes have overestimated the association between birth asphyxia and CP. ${ }^{10}$ Many other risk factors have been identified 
and it is now widely agreed on that the aetiology of CP is multifactorial and that birth asphyxia is one of many associated factors, including not only perinatal, but also antenatal and postnatal factors. ${ }^{11-13}$ Some of these factors may be causal, while some may be part of a series of events that together may be causal. Some factors may not be causal but predictive, or simply signs that the well-being of the fetus or neonate is somehow compromised. ${ }^{4}$

Many antenatal and perinatal factors associated with CP are modified by gestational age. Therefore, stratifying analyses on gestational age can help to clarify the importance of different risk factors within different gestational ages.

The aim of the present study was to, within one birth cohort, investigate multiple known and suggested factors associated with CP stratified by gestational age.

\section{METHOD}

\section{Data sources}

Information about all children born in Skåne (the southernmost county in Sweden with a population of 1286584 in December 2014) in 1995-2014 was identified from the regional medical birth register Perinatal Revision South (PRS). In Sweden, maternal healthcare and delivery service is free of charge and almost all women attend antenatal care. ${ }^{14}$ PRS contains obstetric and neonatal data on all children born in the Southern Healthcare Region of Sweden, since 1995. Information about CP diagnoses was retrieved from the Cerebral Palsy Follow-up Surveillance Programme (CPUP) in December 2016. CPUP was created in 1994 and Skåne was part of the register from the start. It was approved as a national healthcare quality register by the Swedish National Board of Health and Welfare in 2005. CPUP uses the definition of CP recommended by Surveillance of Cerebral Palsy Europe (SCPE). ${ }^{3}{ }^{15}$ Validation of the CP diagnosis and subtype classification for children born in 1994-2012 has been performed by one paediatric neurologist, LW, in cooperation with the patients' doctor. Information about congenital malformations and syndromes were extracted from both PRS and CPUP. Certain minor abnormalities were excluded (preauricular appendices, single umbilical artery, minor skin malformations and undescended testicles).

\section{Source population}

The source population consists of all children born in Skåne between the years 1995 and 2014. There were 250629 registered births during this 21 years study period. Multiple births, those with unknown gestational age or gestational age registered as $<20$ or $>43$ weeks, children with unknown birth weight or birth weight more than $5 \mathrm{SD}$ from the mean, stillbirth/perinatal death as well as children who were born after 2012 (since their CP diagnosis had not yet been validated in accordance with the follow-up programme and did not have a determined subtype), were excluded from the study. This left a cohort of 215217 children of whom 381 had CP that was not due to postnatally acquired brain injury (figure 1 ).

\section{Statistical analyses}

The children were grouped into three categories based on gestational age: term (week $\geq 37+0$ ), moderately or late preterm (week 32-36+6) and very preterm (week $<32)$ births. Descriptive analyses were carried out to investigate the proportion of each of the suggested CP-associated factors. To examine the strength of the association between the factors and $\mathrm{CP}$, we used univariate logistic regression generating ORs and 95\% CIs. If there were less than 10 individuals in the $\mathrm{CP}$ or no $\mathrm{CP}$ group, univariate logistic regression analysis was not performed. The variables that were statistically significantly $(\mathrm{p}<0.05)$ associated with $\mathrm{CP}$ in the respective gestational age group, were included in the multivariable models. The first model investigated the association between the antenatal factors and CP. In the second model, perinatal factors were added, to elucidate to what extent the antenatal risk scores were mediated by those factors.

All statistical analyses were performed in Stata Statistical Software: release V.14.

\section{PATIENT AND PUBLIC INVOLVEMENT}

In this study, no patient or public involvement took place.

\section{RESULTS}

Out of the 215217 children included in the study (figure 1), 206618 (96\%) were born at term, 7355 (3.4 $\%)$ where born moderately or late preterm and 1244 (0.6 $\%)$ were born very preterm (table 1 ). There were 381 children with CP in total, 268 (70.3\%) were born at term, $56(14.7 \%)$ were born moderately or late preterm and 57 $(15.0 \%)$ were born very preterm. Unilateral spastic CP was the most common type in the children born term and moderately or late preterm, while bilateral spastic CP was most common among those born very preterm (table 2). In the descriptive table 1 , it is evident that for some variables there were none or very few $(n<10)$ affected in one or more of the gestational age groups (table 3).

\section{Children born term}

The risk factors significantly associated with $\mathrm{CP}$ in the univariate analyses were: maternal overweight/obesity, small for gestational age, malformation, induction, delivery by elective or emergency caesarian section, Apgar at 5 min below 7 and admission to neonatal care unit (table 3). In the multivariable model including only the antenatal factors, the estimates remained similar to the univariate estimates (table 4). In the multivariable model including also perinatal factors, the effect estimates of malformation decreased but remained significant. Small for gestational age was no longer significantly associated with CP while emergency caesarian, Apgar at 


\section{Children born in Skåne 1995-2014 $(n=250,629)$}

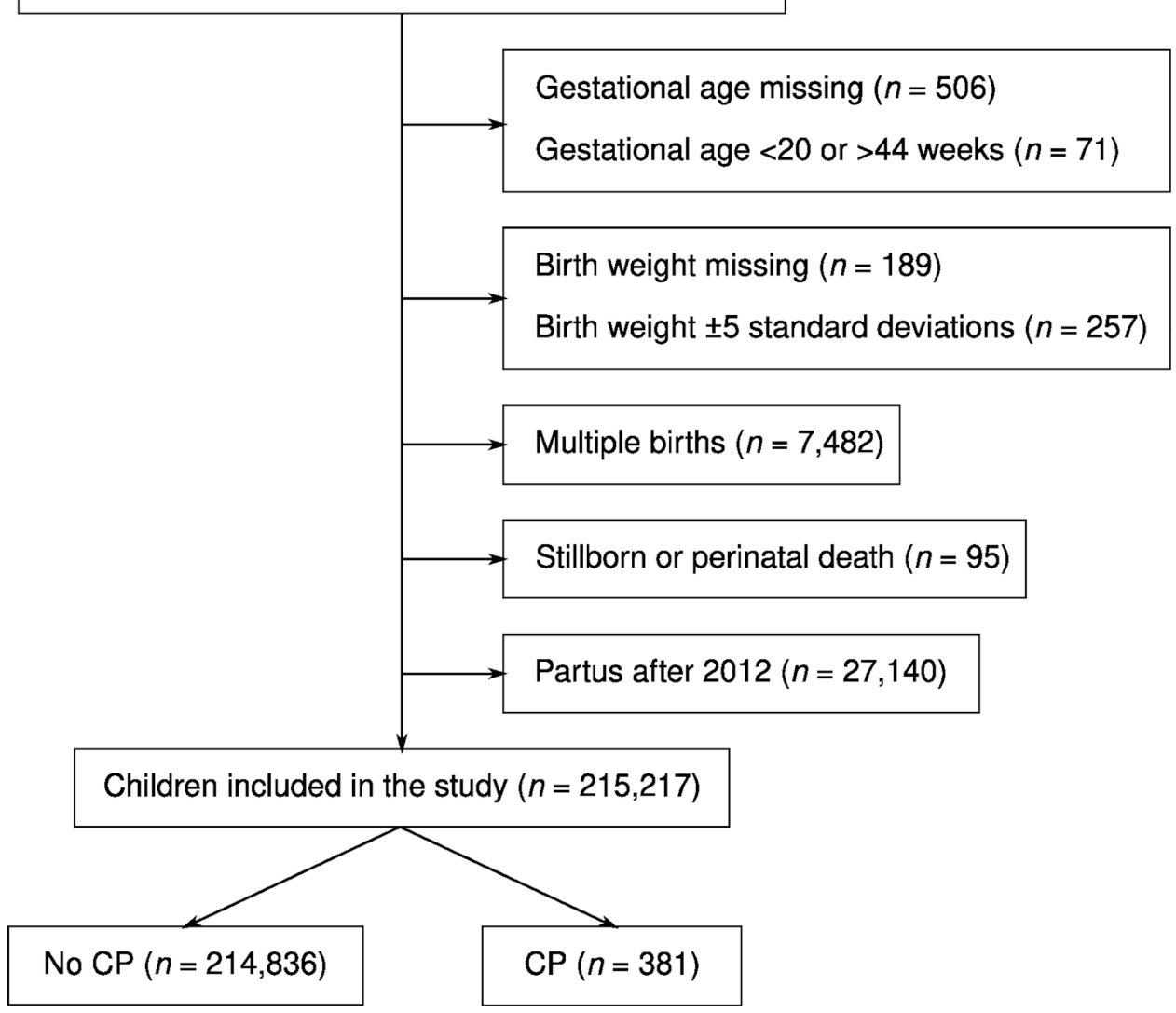

Figure 1 Children included and excluded in the study. Several exclusion criteria may be present in one child. CP, cerebral palsy.

5 min $<7$ and admission to neonatal care were, however, with lower effect estimates than in the univariate analyses.

\section{Children born moderately or late preterm}

The variables significantly associated with $\mathrm{CP}$ in the univariate analyses were: small for gestational age, malformation, delivery by elective or emergency caesarian section and admission to neonatal care (table 3). In the multivariable model, that only include antenatal factors, small for gestational age and malformation remain significantly associated with CP. Finally, in the multivariable model, that also include perinatal variables, the effect estimates, for being small for gestational age is decreased and no longer significant (table 4). Malformation indicates a significantly increased risk of CP in the second model as well as admission to neonatal care, while the effect estimates for emergency or elective caesarian section are lowered and no longer statistically significant.

\section{Children born very preterm}

No variables were significantly associated with $\mathrm{CP}$ in the logistic regression analyses.

\section{DISCUSSION}

In this population-based study among children from the Southern part of Sweden where we had the possibility to include a number of factors simultaneously, both antenatal and perinatal factors are associated with CP. The most pronounced associations observed among term as well as moderately or late preterm born children were for malformation and admission to neonatal care unit. Our results, given the relatively large sample and reliable data from the pregnancy period until delivery and the neonatal period, give weight to factors that have been shown to be associated with CP in prior studies.

The antenatal factor most strongly associated to CP among term children was malformations, suggested as a potential risk factor from earlier studies. ${ }^{16-18}$ Those delivered by caesarian section were also more likely to later receive a CP diagnosis. This result is in line with earlier studies ${ }^{19-21}$ and is most likely due to underlying causes leading to surgery. ${ }^{21}$ There has been a big increase in caesarian sections the last decades but the CP rates have remained relatively stable..$^{22}$ Admission to neonatal care was strongly associated with $\mathrm{CP}$, which can both be because of detrimental factors not recognised in this material such as perinatal infections and because of early signs of CP.

Stillborn or neonatal deaths were not included in this study. It is likely that the same factors that could give rise to symptoms, which would later in life qualify for a CP-diagnosis would also increase the risk of dying before birth 
Table 1 Prevalence of characteristics among term ( $\geq 37$ weeks), moderately or late preterm (32-36 weeks) and very preterm ( $<32$ weeks) children, respectively, with and without cerebral palsy (CP)

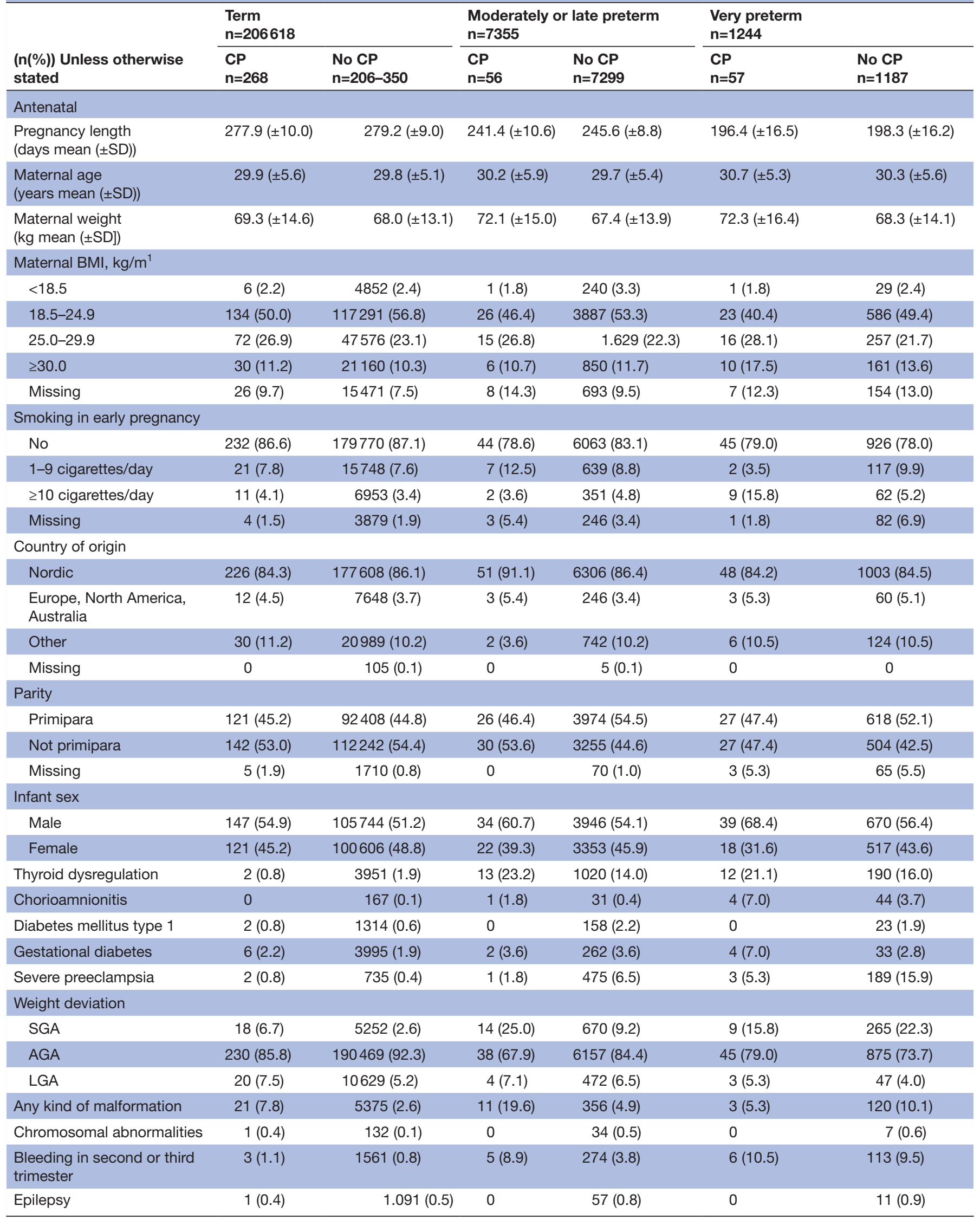


Table 1 Continued

\begin{tabular}{|c|c|c|c|c|c|c|}
\hline \multirow[b]{2}{*}{$\begin{array}{l}(\mathrm{n}(\%)) \text { Unless otherwise } \\
\text { stated }\end{array}$} & \multicolumn{2}{|l|}{$\begin{array}{l}\text { Term } \\
\mathrm{n}=206618\end{array}$} & \multicolumn{2}{|c|}{$\begin{array}{l}\text { Moderately or late preterm } \\
n=7355\end{array}$} & \multicolumn{2}{|c|}{$\begin{array}{l}\text { Very preterm } \\
n=1244\end{array}$} \\
\hline & $\begin{array}{l}C P \\
n=268\end{array}$ & $\begin{array}{l}\text { No CP } \\
n=206-350\end{array}$ & $\begin{array}{l}\mathrm{CP} \\
\mathrm{n}=56\end{array}$ & $\begin{array}{l}\text { No CP } \\
n=7299\end{array}$ & $\begin{array}{l}\mathrm{CP} \\
\mathrm{n}=57\end{array}$ & $\begin{array}{l}\text { No } C P \\
n=1187\end{array}$ \\
\hline \multicolumn{7}{|l|}{ Perinatal } \\
\hline PROM & $6(2.2)$ & $9304(4.5)$ & $11(19.6)$ & $2165(29.7)$ & $15(26.3)$ & $301(25.4)$ \\
\hline \multicolumn{7}{|l|}{ Mode of delivery } \\
\hline Vaginal Instrumental & $13(4.9)$ & $9700(4.7)$ & $1(1.8)$ & $181(2.5)$ & 0 & $4(0.3)$ \\
\hline Sectio, elective & $23(8.9)$ & $11066(5.4)$ & $6(10.7)$ & $382(5.2)$ & $1(1.8)$ & $33(2.8)$ \\
\hline Sectio, emergency & $51(19.0)$ & $14146(6.9)$ & $26(46.4)$ & 2027 (27.8) & $34(59.7)$ & $756(63.7)$ \\
\hline Breech vaginal delivery & $1(0.4)$ & $1088(0.5)$ & $1(1.8)$ & $114(1.6)$ & $1(1.8)$ & $19(1.6)$ \\
\hline Apgar at 5 min below 7 & $40(14.9)$ & $1750(0.1)$ & $9(16.1)$ & $296(4.1)$ & $14(24.6)$ & $311(26.2)$ \\
\hline Admission to neonatal care & $112(41.8)$ & $11820(5.7)$ & $51(91.1)$ & $4266(58.5)$ & $57(100)$ & $1133(95.5)$ \\
\hline
\end{tabular}

AGA, Appropriate for gestational age; BMI, body mass index; LGA, Large for gestational age; PROM, Prelabor rupture of membranes; SGA, Small for gestational age.

or during the neonatal period. If so, the estimates in this study would be affected towards the null.

The link between low parental socioeconomic status (SES) and the risk of having a child with CP have been suggested $^{23}$ and since low SES are linked to the overall risk of preterm birth this could be the pathway. ${ }^{24}$ Several studies have also found that the effect of SES on the prevalence of $\mathrm{CP}$ remains after adjusting for possible mediators such as gestational age and birth weight. ${ }^{25}$ We do not have a specific marker of SES in this study, but smoking is inversely related with SES in Sweden. ${ }^{26}$ In this study, smoking in early pregnancy is not significantly associated with CP, and thus does not support an association between low SES and increased risk of CP. In relation to low birth weight, especially SGA has been identified as a

Table 2 Prevalence of subtypes of cerebral palsy in the three gestational age groups, N (\%)

\begin{tabular}{|c|c|c|c|c|}
\hline Subtypes & $\begin{array}{l}\text { Term } \\
n=268\end{array}$ & $\begin{array}{l}\text { Moderately } \\
\text { or late } \\
\text { preterm } \\
\mathrm{n}=56\end{array}$ & $\begin{array}{l}\text { Very } \\
\text { preterm } \\
\mathrm{n}=57\end{array}$ & $\begin{array}{l}\text { Total } \\
\mathrm{n}=381\end{array}$ \\
\hline Unilateral spastic & 95 (35.5) & 22 (39.3) & 11 (19.3) & $128(33.6)$ \\
\hline $\begin{array}{l}\text { Bilateral spastic } \\
\text { diplegia }\end{array}$ & 55 (20.5) & $20(35.7)$ & $41(71.9)$ & $116(30.5)$ \\
\hline $\begin{array}{l}\text { Bilateral spastic } \\
\text { tetraplegia }\end{array}$ & $10(3.7)$ & 0 & $1(1.8)$ & $11(2.9)$ \\
\hline Dyskinetic & $60(22.4)$ & $6(10.7)$ & $1(1.8)$ & $67(17.6)$ \\
\hline Ataxic & 32 (11.9) & $5(8.9)$ & $2(3.5)$ & 39 (10.2) \\
\hline Non-classifiable & $16(5.9)$ & $3(5.4)$ & $1(1.8)$ & 20 (5.3) \\
\hline
\end{tabular}

risk factor for $\mathrm{CP}$ in term babies, ${ }^{12}{ }^{27}$ however, we did not find that in ours study.

Genetic involvement has been identified in CP, but we do not have any genetic information in this study, except about occasional genetic syndrome. Depending on genetic susceptibility, environmental factors might be more or less detrimental and understanding such relations better might open up for directed preventive measures. ${ }^{28}$ In combination with this registry study, maternal early pregnancy biobank blood samples from most of the participants are available, and will be analysed regarding toxicological risk factors. Another way to further understand the complexity between different risk factors and $\mathrm{CP}$ would be to combine registry data with a biobank that include important biomarkers including genetic markers from the participants themselves.

An important strength of the study lies in our population-based study design. Many prior studies have studied one or a few suggested risk factors at a time whereas our design allowed us to investigate several previous suggested factors associated with $\mathrm{CP}$ simultaneously. Moreover, the data were routinely and prospectively collected, which is an important strength since it eliminates the risk for recall bias.

Another strength of our study is the large sample size that enabled us to stratify all analyses on gestational age. Still, it is important to bear in mind that preterm birth itself is an abnormal event, why a control group matched on prematurity contains, per definition, neonates born preterm due to some kind of pathological process, ${ }^{29}$ which affects the risk estimates. This must be taken into account 
Table 3 Univariate estimates obtained from logistic regressions between antenatal and perinatal factors and cerebral palsy (CP) among term ( $\geq 37$ weeks), moderately or late preterm (32-36 weeks) and very preterm $(<32$ weeks) children, respectively

$\begin{array}{lll}\text { Term gestational age } & \begin{array}{l}\text { Moderately or late preterm } \\ \text { gestational age } 32-36\end{array} & \begin{array}{l}\text { Very preterm gestational } \\ \text { age }<32\end{array}\end{array}$

\section{Antenatal}

Maternal age (years)

\begin{tabular}{|c|c|c|c|}
\hline$<20$ & $1.18(0.53,2.66)$ & $2.58(0.80,8.36)$ & $0.55(0.07,4.08)$ \\
\hline $20-39$ & ref & ref & ref \\
\hline$\geq 40$ & $1.46(0.80,2.67)$ & $1.59(0.49,5.12)$ & $0.31(0.04,2.31)$ \\
\hline \multicolumn{4}{|l|}{ Maternal BMI $\left(\mathrm{kg} / \mathrm{m}^{2}\right)$} \\
\hline$<18.5$ & $1.08(0.48,2.45)$ & $0.62(0.08,4.61)$ & $0.88(0.11,6.73)$ \\
\hline $18.5-24.9$ & ref & ref & ref \\
\hline$>25$ & $1.30(1.00,1.68)^{*}$ & $1.27(0.71,2.26)$ & $1.58(0.89,2.82)$ \\
\hline \multicolumn{4}{|l|}{ Smoking in early pregnancy } \\
\hline No & ref & ref & ref \\
\hline Yes & $1.09(0.75,1.58)$ & $1.25(0.61,2.57)$ & $1.26(0.64,2.49)$ \\
\hline \multicolumn{4}{|l|}{ Country of origin } \\
\hline Nordic & ref & ref & ref \\
\hline Europe, North America, Australia & $1.23(0.69,2.20)$ & $1.51(0.47,4.86)$ & $1.04(0.31,3.45)$ \\
\hline Other & $1.12(0.77,1.64)$ & $0.33(0.08,1.37)$ & $1.01(0.42,2.41)$ \\
\hline \multicolumn{4}{|l|}{ Parity } \\
\hline Previous child/children & ref & ref & ref \\
\hline No previous child & $1.04(0.81,1.32)$ & $0.71(0.42,1.20)$ & $0.82(0.47,1.41)$ \\
\hline \multicolumn{4}{|l|}{ Infant sex } \\
\hline Male & $1.16(0.91,1.47)$ & $1.31(0.77,2.25)$ & $1.67(0.95,2.96)$ \\
\hline Female & ref & ref & ref \\
\hline Thyroid dysregulation (yes vs no) & $\dagger$ & $1.86(1.00,3.47)$ & $1.40(0.73,2.69)$ \\
\hline \multicolumn{4}{|l|}{ Weight deviation } \\
\hline SGA & $2.84(1.76,4.59)$ ा & $3.39(1.83,6.28) \pi$ & $0.66(0.32,1.37)$ \\
\hline AGA & ref & ref & ref \\
\hline LGA & $1.56(0.98,2.46)$ & $1.37(0.49,3.86)$ & $1.24(0.37,4.14)$ \\
\hline Malformation (yes vs no) & $3.18(2.03,4.97)$ ा & $4.77(2.44,9.30)$ ा & $\dagger$ \\
\hline \multicolumn{4}{|l|}{ Perinatal } \\
\hline PROM (yes vs no) & & $0.58(0.30,1.12)$ & $1.05(0.57,1.92)$ \\
\hline \multicolumn{4}{|l|}{ Mode of delivery } \\
\hline Vaginal & ref & ref & ref \\
\hline Vaginal instrumental & $1.27(0.72,2.24)$ & $1.16(0.16,8.67)$ & $\S$ \\
\hline Sectio, elective & $1.97(1.28,3.05) \ddagger$ & $3.31(1.33,8.20)^{*}$ & $0.56(0.07,4.33)$ \\
\hline Sectio, emergency & $3.42(2.51,4.68) \uparrow$ & $2.70(1.53,4.77) \ddagger$ & $0.84(0.48,1.46)$ \\
\hline Induction (yes vs no) & $1.61(1.14,2.28) \ddagger$ & $\dagger$ & $\dagger$ \\
\hline Apgar at 5 min (below vs above 7 ) & $20.6(14.66,28.91) \rrbracket$ & $\dagger$ & $0.93(0.50,1.73)$ \\
\hline Admission to neonatal care (yes vs no) & $11.82(9.26,15.07)$ ๆ & $7.25(2.89,18.19)$ п & $\S$ \\
\hline
\end{tabular}

ORs with $95 \%$ Cls are given.

Bold values indicate $95 \%$ significat estimates.

*sign. $<0.05$

tOR not calculated because $\mathrm{n}<10$ in either $\mathrm{CP}$ or no $\mathrm{CP}$-group.

łsign. $<0.01$.

§OR not possible to calculate because $100 \%$ in CP or no CP group.

Isign. $<0.001$

AGA, Appropriate for gestational age; BMI, body mass index; LGA, Large for gestational age; SGA, Small for gestational age. 
Table 4 Univariate and multivariable estimates obtained from logistic regressions between antenatal and perinatal factors and cerebral palsy among term ( $\geq 37$ weeks) and moderately or late preterm (32-36 weeks) children, respectively

\begin{tabular}{|c|c|c|c|}
\hline & \multirow[b]{2}{*}{$\begin{array}{l}\text { Univariate models } \\
\text { (same estimates as in table } 3 \text { ) }\end{array}$} & \multicolumn{2}{|l|}{ Multivariable models } \\
\hline & & $\begin{array}{l}\text { Including only antenatal } \\
\text { variables }\end{array}$ & $\begin{array}{l}\text { Including antenatal and } \\
\text { perinatal variables }\end{array}$ \\
\hline \multicolumn{4}{|l|}{ Antenatal variables } \\
\hline \multicolumn{4}{|l|}{ Maternal BMI $\left(\mathrm{kg} / \mathrm{m}^{2}\right)$} \\
\hline$>25$ & $1.30(1.00,1.68)^{\star}$ & $1.28(0.98,1.66)$ & $1.10(0.84,1.43)$ \\
\hline \multicolumn{4}{|l|}{ Small or large for gestational age } \\
\hline SGA & $2.84(1.76,4.59) \ddagger$ & $2.24(1.28,3.93) \dagger$ & $1.07(0.60,1.91)$ \\
\hline AGA & ref & ref & ref \\
\hline Induction (yes vs no) & $1.61(1.14,2.28) \dagger$ & & $1.19(0.82,1.75)$ \\
\hline \multicolumn{4}{|l|}{ Delivery mode } \\
\hline Vaginal delivery & ref & & ref \\
\hline Vaginal instrumental delivery & $1.27(0.72,2.24)$ & & $0.71(0.39,1.30)$ \\
\hline Elective ceasarian section & $1.97(1.28,3.05) \dagger$ & & $1.59(1.00,2.53)$ \\
\hline Emergency ceasarian section & $3.42(2.51,4.68) \ddagger$ & & $1.56(1.08,2.24)^{\star}$ \\
\hline Apgar at 5 min (below vs above 7 ) & $20.6(14.66,28.91) \ddagger$ & & $4.45(2.89,6.84) \ddagger$ \\
\hline Admission to neonatal care unit (yes vs no) & $11.82(9.26,15.07) \ddagger$ & & $7.06(5.19,9.62) \ddagger$ \\
\hline Moderately or late preterm & $n=7355$ & $\mathrm{n}=7275$ & $n=7275$ \\
\hline \multicolumn{4}{|l|}{ Perinatal variables } \\
\hline \multicolumn{4}{|l|}{ Delivery mode } \\
\hline Vaginal delivery & ref & & ref \\
\hline Vaginal instrumental delivery & $1.16(0.16,8.67)$ & & $0.95(0.13,7.10)$ \\
\hline Elective ceasarian section & $3.31(1.33,8.20)^{\star}$ & & $2.15(0.85,5.44)$ \\
\hline Emergency ceasarian section & $2.70(1.53,4.77) \dagger$ & & $1.61(0.88,2.95)$ \\
\hline Admission to neonatal care unit (yes vs no) & $7.25(2.89,18.19) \ddagger$ & & $5.05(1.96,13.00) \dagger$ \\
\hline
\end{tabular}

One of the multivariable models includes only antenatal variables whereas the other model includes antenatal and perinatal variables.

ORs with $95 \% \mathrm{Cls}$ are shown.

Bold values indicate $95 \%$ significant estimates.

*sign. $<0.05$.

†sign. $<0.01$.

$\ddagger$ sign. $<0.001$

BMI, body mass index.

when interpreting results of analyses stratified by gestational age. However, in this study, the focus of our analysis was to analyse the importance of different suggested risk factors within each gestational age group, and doing so we get an estimate of the relative importance of this risk factor for children that for one reason or another were born term, moderately or late preterm or very preterm.

Finally, and importantly, the use of the quality register CPUP for case ascertainment is a major strength, since all the CP cases have been diagnosed independently of 
this study. CPUP has very good coverage and includes in principle all children with $\mathrm{CP}$ in southern Sweden. ${ }^{2}$ The definition of CP used in the CPUP is the same as in earlier studies from Sweden and the SCPE. The ascertainment of $\mathrm{CP}$ in the region was solid; a senior neuropaediatrician (LW) performed regular inventories to find all children with signs of $\mathrm{CP}$ in the area, and validated the $\mathrm{CP}$ diagnosis and subtype after the child's fourth birthday.

In conclusion, we investigated several of the previously suggested factors associated with $\mathrm{CP}$ in one populationbased study. Many prior studies have been focused on studying one or a few factors at a time, whereas our design allowed us to investigate several factors simultaneously in one material. Our results support and strengthen previous findings.

Contributors Substantial contributions to the conception or design of the work (AJ, $\mathrm{AS}, \mathrm{KK}, \mathrm{LW}$ and $\mathrm{LR}$ ). Acquisition of data (KK). Analysis and interpretation of data (AJ, AS, KK, LW and LR). Drafting the work (AS). Revising the draft (AJ, AS, KK, LW and LR). Final approval of draft (AJ, AS, KK, LW and LR).

Funding This study is part of the ReproUnion collaborative study, cofinanced by the European Union, Intereg V Öresund-Kattegat-Skagerrak (NYPS 20200407).

Patient and public involvement Patients and/or the public were not involved in the design, or conduct, or reporting, or dissemination plans of this research.

Patient consent for publication Not required.

Ethics approval The study was approved by the Regional Ethical Review Board, Lund, Sweden.

Provenance and peer review Not commissioned; externally peer reviewed.

Data availability statement Data are available on reasonable request. In the information given to the project participants, it was stated that the collected information would only be available to the researchers working on the project. This restriction on sharing data was a part of the documents reviewed and approved by the regional ethical review board, Regionala etikprövningsnämnden i Lund. A new application to the ethical review board is needed to let the board consider whether access to data about the participants could be given to external researchers. Applications can be sent via digital forms. Homepage: https://etikprovningsmyn digheten.se/. Phone: $+46-010-4750800$. The request for data can be sent to the guarantor of the project: lars.rylander@med.lu.se.

Open access This is an open access article distributed in accordance with the Creative Commons Attribution Non Commercial (CC BY-NC 4.0) license, which permits others to distribute, remix, adapt, build upon this work non-commercially, and license their derivative works on different terms, provided the original work is properly cited, appropriate credit is given, any changes made indicated, and the use is non-commercial. See: http://creativecommons.org/licenses/by-nc/4.0/.

\section{ORCID iD}

Anna Jöud http://orcid.org/0000-0001-7192-4911

\section{REFERENCES}

1 Odding E, Roebroeck ME, Stam HJ. The epidemiology of cerebral palsy: incidence, impairments and risk factors. Disabil Rehabil 2006;28:183-91.

2 Westbom L, Hagglund G, Nordmark E. Cerebral palsy in a total population of 4-11 year olds in southern Sweden. prevalence and distribution according to different CP classification systems. BMC Pediatr 2007;7:41.

3 Rosenbaum P, Paneth N, Leviton A, et al. A report: the definition and classification of cerebral palsy April 2006. Dev Med Child Neurol Suppl 2007;109:8-14.
4 Blair E, Stanley FJ. Issues in the classification and epidemiology of cerebral palsy. Ment Retard Dev Disabil Res Rev 1997;3:184-93.

5 Stavsky M, Mor O, Mastrolia SA, et al. Cerebral Palsy-Trends in epidemiology and recent development in prenatal mechanisms of disease, treatment, and prevention. Front Pediatr 2017;5:21.

6 Himmelmann K, Uvebrant P. The Panorama of cerebral palsy in Sweden part XII shows that patterns changed in the birth years 2007-2010. Acta Paediatr 2018;107:462-8.

7 Hollung SJ, Vik T, Lydersen S, et al. Decreasing prevalence and severity of cerebral palsy in Norway among children born 1999 to 2010 concomitant with improvements in perinatal health. Eur $J$ Paediatr Neurol 2018;22:814-21.

8 Sellier E, Platt MJ, Andersen GL, et al. Decreasing prevalence in cerebral palsy: a multi-site European population-based study, 1980 to 2003. Dev Med Child Neurol 2016;58:85-92.

9 Kruse M, Michelsen SI, Flachs EM, et al. Lifetime costs of cerebral palsy. Dev Med Child Neurol 2009;51:622-8.

10 Ellenberg JH, Nelson KB. The association of cerebral palsy with birth asphyxia: a definitional quagmire. Dev Med Child Neurol 2013;55:210-6.

11 Himmelmann K, Ahlin K, Jacobsson B, et al. Risk factors for cerebral palsy in children born at term. Acta Obstet Gynecol Scand 2011;90:1070-81.

12 McIntyre S, Taitz D, Keogh J, et al. A systematic review of risk factors for cerebral palsy in children born at term in developed countries. Dev Med Child Neurol 2013;55:499-508.

13 Mclntyre S, Blair E, Badawi N, et al. Antecedents of cerebral palsy and perinatal death in term and late preterm singletons. Obstet Gynecol 2013;122:869-77.

14 Berglund A. Mödrahälsovård, Sexuell och Reproduktiv Hälsa, 2008. Available: https://www.sfog.se/natupplaga/ARG76web4a328b700d76-474e-840e-31f70a89eae9.pdf

15 Johnson A. Prevalence and characteristics of children with cerebral palsy in Europe. Dev Med Child Neurol 2002;44:633-40.

16 Garne E, Dolk H, Krägeloh-Mann I, et al. Cerebral palsy and congenital malformations. Eur J Paediatr Neurol 2008;12:82-8.

17 Coorssen EA, Msall ME, Duffy LC. Multiple minor malformations as a marker for prenatal etiology of cerebral palsy. Dev Med Child Neurol 1991;33:730-6.

18 Jystad KP, Strand KM, Bjellmo S, et al. Congenital anomalies and the severity of impairments for cerebral palsy. Dev Med Child Neurol 2017;59:1174-80.

19 Ahlin K, Himmelmann K, Hagberg G, et al. Non-Infectious risk factors for different types of cerebral palsy in term-born babies: a population-based, case-control study. BJOG 2013;120:724-31.

20 Thorngren-Jerneck K, Herbst A. Perinatal factors associated with cerebral palsy in children born in Sweden. Obstet Gynecol 2006;108:1499-505.

21 O'Callaghan M, MacLennan A, Delivery C. Cesarean delivery and cerebral palsy: a systematic review and meta-analysis. Obstet Gynecol 2013;122:1169-75.

22 MacLennan AH, Thompson SC, Gecz J. Cerebral palsy: causes, pathways, and the role of genetic variants. Am J Obstet Gynecol 2015;213:779-88.

23 Forthun I, Strandberg-Larsen K, Wilcox AJ, et al. Parental socioeconomic status and risk of cerebral palsy in the child: evidence from two Nordic population-based cohorts. Int J Epidemiol 2018;47:1298-306.

24 Stewart A, Graham E. Preterm birth: an overview of risk factors and obstetrical management. Dev Disabil Res Rev 2010;16:285-8.

25 Solaski M, Majnemer A, Oskoui M. Contribution of socio-economic status on the prevalence of cerebral palsy: a systematic search and review. Dev Med Child Neurol 2014;56:1043-51.

26 Socialstyrelsen. 10_Tobaksvanor [online]. Available: http://www. socialstyrelsen.se/publikationer2009/2009-126-71/Documents/10_ Tobaksvanor.pdf [Accessed 2 Feb 2018].

27 Ahlin K, Jacobsson B, Nilsson S, et al. Antecedents and neuroimaging patterns in cerebral palsy with epilepsy and cognitive impairment: a population-based study in children born at term. Acta Obstet Gynecol Scand 2017;96:828-36.

28 Fahey MC, Maclennan AH, Kretzschmar D, et al. The genetic basis of cerebral palsy. Dev Med Child Neurol 2017;59:462-9.

29 Greenwood C, Yudkin P, Sellers S, et al. Why is there a modifying effect of gestational age on risk factors for cerebral palsy? Arch Dis Child Fetal Neonatal Ed 2005;90:F141-6. 